\title{
Stormwater Management in Urban Areas by Combining Traditional and Alternative Techniques: If the Subdivision Mimosas in Marrakech
}

\author{
Rafik Ismail ${ }^{*}$, Serroukh Mostapha, KhattatI Mourad, Masmoudi Hakim \\ Faculty of Tetouan, Abdelmalek Essaadi University, Morocco
}

Copyright $(2016$ by authors, all rights reserved. Authors agree that this article remains permanently open access under the terms of the Creative Commons Attribution License 4.0 International License

\begin{abstract}
The article presents more specifically how the stormwater management builds the overall plan and the problems that can be encountered during the implementation of improvements. With the growing waterproofing of cities and activity zones, the long rains or heavy rain storms, causing downstream flooding problems (or locally) as well as any shortfall in groundwater recharge underlying and disrupt the capacity of treatment plants and exceeds that of unit drainage systems of water, sustainable drainage system are tested in different countries. Better management and control of urban discharges during rainy weather is necessary, designing a alternative and integrated management model based on ecological engineering techniques, themselves adding value to natural purification and water filtration capacity allows not having to continually increase the capacity of the sewer systems, pipes and retention ponds hard, which are sources of technical, property, financial, environmental, social, legal, security and future maintenance costs.
\end{abstract}

Keywords Rainfed Waters, Alternatives Techniques, Sustainable Development, Watershed, Water Resources

\section{Introduction}

Faced with the expansion of urban areas and the challenges currently posed by climate hazards, storm water management, must involve the existing traditional techniques with innovative alternative techniques with emphasis on sustainable development. One of the most important goals is limiting soil sealing. Stormwater is managed surface via the various possible retention techniques including: Ditches or tied, trench retention, infiltration, infiltration wells, storage tank and floor roof. Large green corridors calling for the walk but also serve as overflow when centennial rain. Subdivisions can benefit also of a system of retention of rain water or buried superficial provided for watering public areas.

The idea supports this project is to truly integrate the extension of technical innovators of stormwater management in existing and not merely to juxtapose amenities.

\section{Materials and Methods}

We proceeded to the integration of a storm water management through the combination of traditional and alternative techniques in a program that includes the construction of a housing estate, as a concrete example we have illustrated this innovative strategy by a study cases of subdivision "MIMOSAS" located in Marrakech and which aims to allow the integration of 2000 inhabitants. The development project is located in the Municipality Marrakech - Menara.

This town is located to the west of the river Issil, the medina and Kasbah-Méchouar. His urbanized part includes all modern sectors of Guéliz and Hivernage and the latest extensions of the road Safi and Mohammadia city. The town includes the former industrial area called "industrial district". (ONEM 2007). 


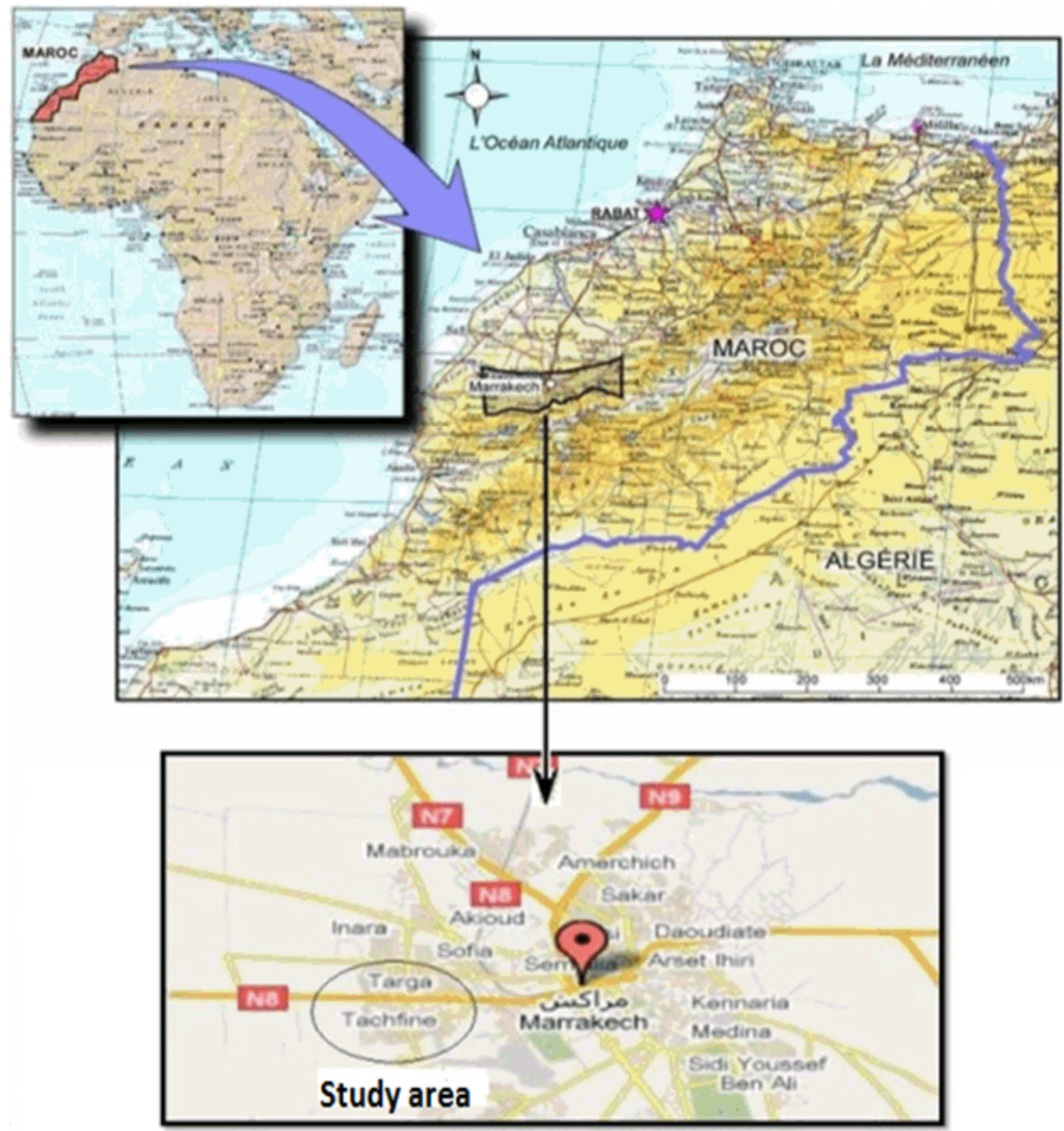

Figure 1. Presentation of the study area (JICA MATEE, ABHT, 2007).

The main steps are the following:

- Respond to the plot.

- Decentralize retention areas and mobilize public spaces for hydraulic needs; water will be retained in the green areas and even in minerals multifunctional spaces: squares, etc.

- Encourage surface water pathways

- Identify and secure exceptional water paths this project has the dual control of operational work mission of public spaces and implementation of regulatory dossier under environmental and water law.

In any sanitation project, determining the dimensions to be given adequate sanitation through the calculation of the required discharge in this context the study area will be, at first, cut into individual watersheds. Peak flows and needs in terms of storage are evaluated according to these watersheds. 


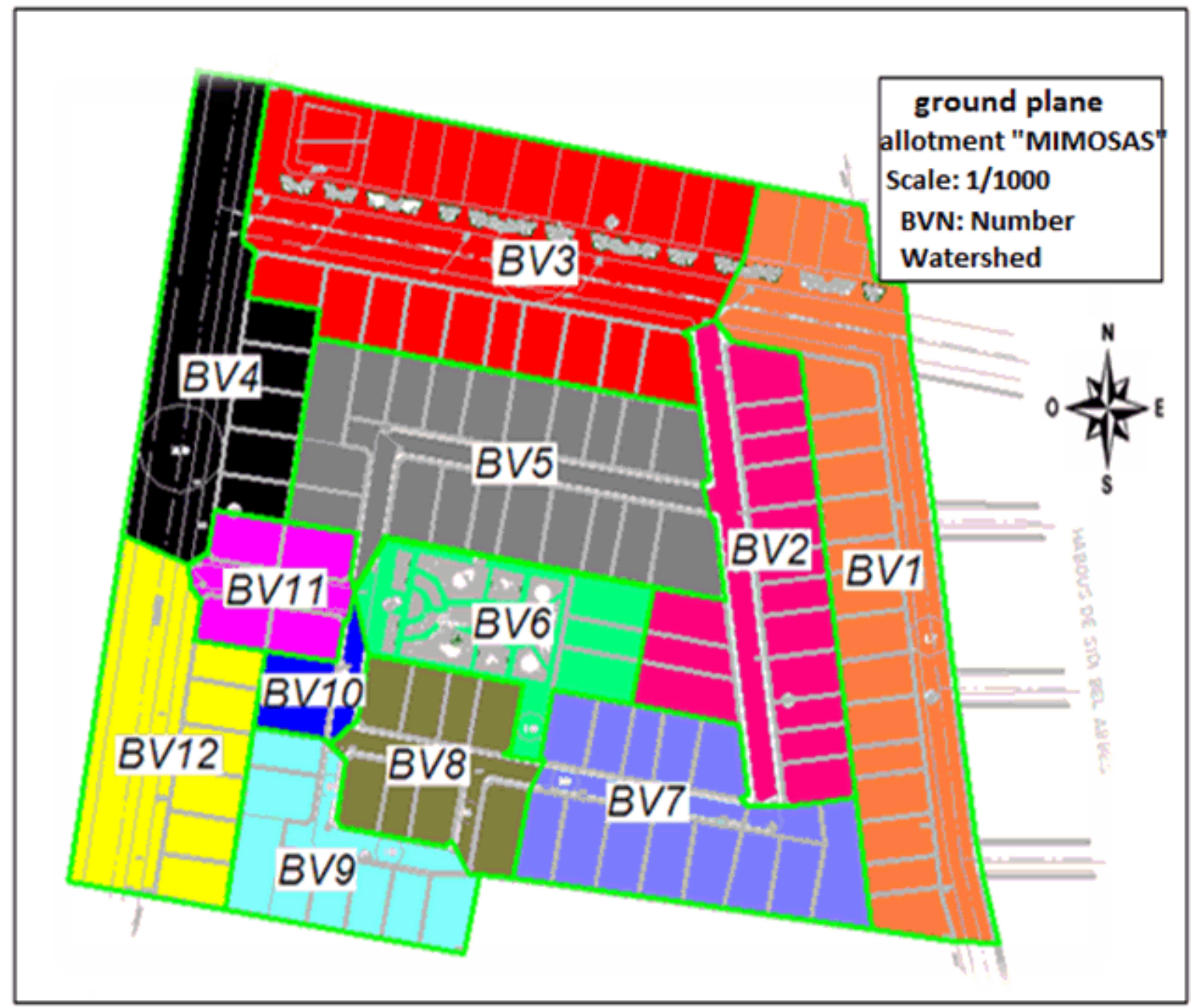

Figure 2. Delineation of watersheds where the subdivision "Mimosas".

The combination with an alternative technique requires a recalibration of volumes in different parks on the basis of an analysis of the topography and the uses contemplated for these areas: here, to make arbitration between some valleys and the central green area

Retention goals are decided on the basis of type of simulations "linear reservoir", catchment by catchment. The impluviums are then assembled. The assembly is implemented as Excel. The calculation tool allows combining several places rainwater retention, with serial operating possibilities of some of them: this basin can surverser in another.

Different scenarios were tested, adjusting output rates different "pools". In some cases, in fact, for a given sub-area, it is possible to store the entire volume on site. In other cases, it is preferable to transfer the volume downstream. Other cases are intermediate, partially on-site storage (short rains) and occasional overflow to another place of detention downstream. The goal is to find a satisfactory distribution of the retention volumes based on inputs, available space, topography, water paths, etc ...

The work is formalized in a very concrete way in the form of regular design combination involving the three-pronged environmental, economic and social. These associations referred to fit together, the As, assumptions retention and water paths, with a simultaneous working drawings plan and calculation. The design is integrated rather than sequenced only way to effectively manage stormwater surface.

This operation conducted with planners and landscapers, illustrates how the combination of alternative techniques shapes a townscape environmentally whatever the urban context.

\section{Urban Space Mastery Flood}

Urban space could many of the alternative techniques. However, the hydraulic function is this time relegated to the background. This is public space that premium. These public spaces, walking areas which are in waters only when it has rained, allow for management urban 'rainwater

\section{Green Roofs Terraces}

Vegetated roofs participate outside their aesthetic interest, economic and environmental dimension of the scenic landscape. [2]

\section{Devices for Collection and Transportation of Rainwater}

The valleys used to weave a network of stormwater high points at the low point of the site. They will make visible a subtle topography of the site. [1] 


\section{Planted Sand Filter for Stormwater Pollution}

The most sustainable solutions are intentionally used. The plants were selected from list drawn phytoremédiantes most efficient plants. Depending on future uses of the site (passing and risk of degradation / pollution), the final choice fell on the most robust plants, and the precedence depending on the theoretical efficiency. In addition to their functions, participate in the plants fill the landscape is not urban but decorates a complex interaction of uses and adaptation to site, yard and long.

\section{Case Study: Subdivision "MIMOSAS"}

Reduce runoff as part of the organization of "MIMOSAS" sector, the use of soil sealing technology reduces runoff intake, limiting the sealing surfaces.

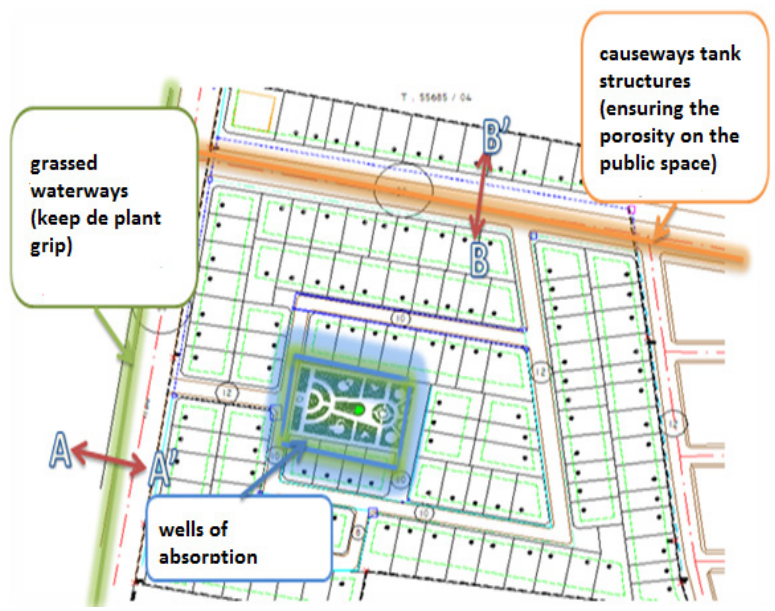

Figure 3. Examples of alternative techniques to limit waterproofing

The development of large grassy areas, pedestrian paths in porous coatings, roof terraces, pathways of vegetated water, reduces stormwater inputs from 5 to $10 \%$ [7] and decreases in proportion to the storage volumes to predict.

\section{Noues or Grassed Waterways}

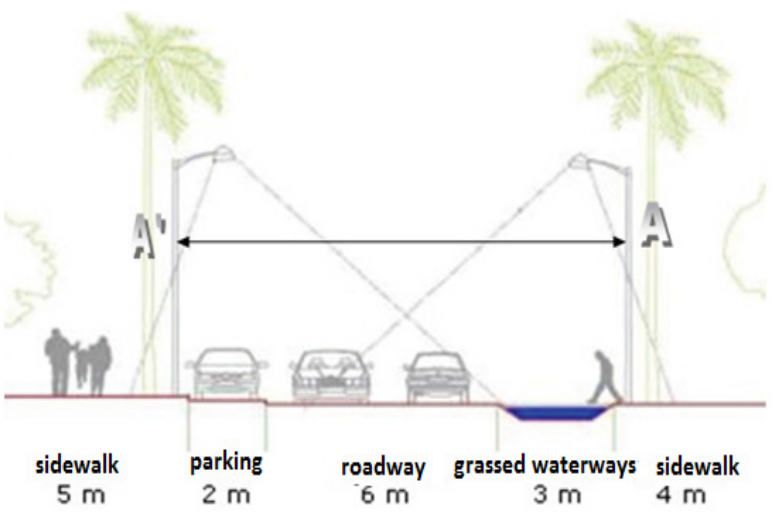

Figure 4. The section AA 'Principle of the collection device and transport rainwater by open pit or pit grassy Noue (S.GuideEnR HQE).

The collection and delivery of open storm water runoff by becoming the holder of a green frame declining buried the network. They allow prioritizing flow axes according to the device shown in Figure 4.
This open network based on a gravity pathway, has the advantage of affirming the presence of water on the site. It also contributes to the visibility of the area, its hierarchy; it reinforces its coherence as each island is, of necessity, attached to this same natural frame.

\section{Roadways Tank Structure}

Reservoir structure roadways (CSR) aim to clip the runoff peak flows by temporarily storing rain in the body of the floor.

The hydraulic operation of the tank floor structure is provided by three functions: an injection of water in the structure, a temporary storage of water and an outlet.

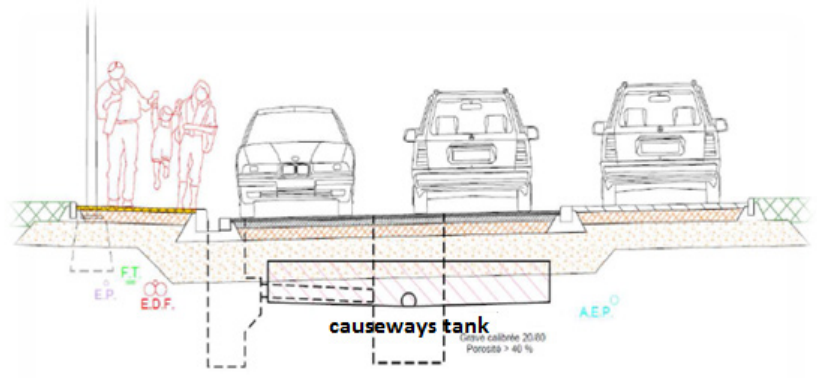

Figure 5. Principles of collection and transport device rainwater tank structure by Pavements (S.GuideEnR HQE).

\section{Well of Entry}

Well absorption is a variable depth book (a few meters to tens of meters) for storage and direct discharge of stormwater into the ground. This technique is rather predestined for use in the plot. There are different types of wells: hollow shafts, wells filled with gravel for a water purification and masonry wells or nozzles. This type of structure can be implemented in less permeable zones in the surface.

Retention goals are decided on the basis of type of simulations "linear reservoir", catchment by catchment. The impluviums are then assembled.

The simulations use of project rainy built from local rainfall coefficients. The overall leak rate target will be set at a level of vicennal protection.

The design is made by combining several places rainwater retention, with serial operating possibilities of some of them: this basin can surverser in another.

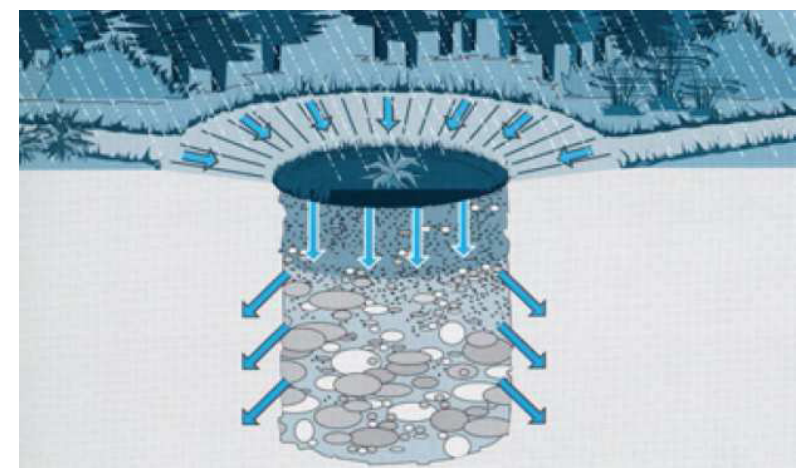

Figure 6. Principles of collection and transport device stormwater by sinks (S.GuideEnR HQE). 


\section{Results}

Based on the initial composition map, and after simulation scenarios the choice of combined techniques is stabilized on the most

\section{Suitable Places of Detention}

The organization of water paths between different detention facilities shows how the output rates of each place of detention are returned. He then used to set watersheds calculations (assemblies in series or in parallel).

The calculation returns the results corresponding to the place of detention concerned with the alternative technique of stormwater management: input flow (unregulated) output rate (regulated) volume stored.

\section{The Use of These Alternative Techniques in Water Management Permit}

- Optimization in conventional techniques

The combination of both classical and alternative techniques reduces the diameters of the manifolds stormwater to $50 \%$ along with optimized on the pipe length that will route these water downstream, the optimization depends on the goals and rate the techniques used.

- The optimization on costs

It is therefore proposed to compare the cost of some alternative systems to conventional systems that are most similar (similar function).

Take the example of a valley with a sanitation pipe

Assumptions: - Noue: width $3 \mathrm{~m}$ - depth 0,5 m - $1 \mathrm{~m}^{3}$ volume stored - Network EP (rain water): driving DN (Nominal Diameter) 600- depth $2.50 \mathrm{~m}$ - Volume $1 \mathrm{~m}^{3}$ stored.

We Recognizes valleys can be more expensive than conventional systems. This results from the fact that these valleys consume way (public or private), contrary to sanitation networks are buried. Thus, the strong land pressure in a very dense environment can make these more expensive techniques. Without taking into account the cost of land, the valleys would be the most economical.

Table 1. Results sizing stormwater

\begin{tabular}{|c|c|c|c|c|c|c|c|c|c|}
\cline { 2 - 10 } \multicolumn{1}{c|}{} & $\begin{array}{c}\text { référence } \\
\text { Du } \\
\text { Watershed }\end{array}$ & Slope $(\mathbf{m} / \mathbf{m})$ & $\begin{array}{c}\text { Lenght } \\
(\mathbf{m})\end{array}$ & $\begin{array}{c}\text { Corrected } \\
\text { Flow(Q) } \\
(\mathbf{m} 3 / \mathbf{s})\end{array}$ & $\begin{array}{c}\text { Calculated } \\
\text { diametre } \\
(\mathbf{m m})\end{array}$ & $\begin{array}{c}\text { Diametre } \\
\text { selected } \\
(\mathbf{m m})\end{array}$ & $\begin{array}{c}\text { Speed } \\
(\mathbf{m} / \mathbf{s})\end{array}$ & $\begin{array}{c}\text { Speed } \\
(1 / 100 \mathrm{Q}) \\
(\mathbf{m} / \mathbf{s})\end{array}$ & Validation \\
\hline Manifold1 & BV1 & 0,005 & 164,07 & 0,02 & 234 & 400 & 0,88 & 0,48 & Validate \\
\hline Antenna1 & BV2 & 0,005 & 51,1 & 0,06 & 317,49 & 400 & 0,88 & 0,48 & Validate \\
\hline Manifold2 & A3 & 0,005 & $\mathbf{2 8 1 , 1 6}$ & 0,13 & 429,35 & 500 & \multicolumn{2}{|c|}{ Optimization of } \\
\hline Manifold3 & A5 & 0,005 & $\mathbf{2 1 5 , 0 9}$ & $\mathbf{0 , 2 3}$ & 520,65 & 600 & \multicolumn{1}{|c|}{ the linear pipe } \\
\hline Antennad & BV6 & 0,005 & 31,67 & 0,15 & 447,64 & 500 & 1,04 & $0,5 /$ & Validate \\
\hline Manifold4 & BV7 & 0,005 & 188,56 & 0,05 & 478,85 & 500 & 1,04 & 0,57 & Validate \\
\hline Manifold5 & A8 & 0,005 & 114,18 & 0,23 & 525,12 & 600 & 1,19 & 0,66 & Validate \\
\hline
\end{tabular}

Table 2. Financial comparison between a conventional technique and another alternative.

\begin{tabular}{|c|c|c|c|}
\hline \multicolumn{2}{|c|}{ Grassed waterways } & \multicolumn{2}{|c|}{ Sewerage system } \\
\hline Designation & $\begin{array}{l}\text { Cost per linear } \\
\text { meter (\$) }\end{array}$ & Designation & $\begin{array}{l}\text { Cost per linear } \\
\text { meter (\$) }\end{array}$ \\
\hline \multicolumn{2}{|c|}{ Investment } & \multicolumn{2}{|c|}{ Investment } \\
\hline Spoil & 10,00 & frisking & 125,00 \\
\hline Sealing & 55,00 & Pipe DN600 & 95,00 \\
\hline Topsoil & 20,00 & Structures & 60,00 \\
\hline Seding & 15,00 & test & 7,00 \\
\hline Structures & 40,00 & various repairs & 50,00 \\
\hline land occupied & 300,00 & & \\
\hline Maintenance 20 years & 120,00 & Maintenance 20 years & 100,00 \\
\hline Total Investment & 560,00 & Total Investment & 437,00 \\
\hline
\end{tabular}




\section{Discussion}

The classic and alternative combination technique helps control at source and assumed to infiltrate locally and not just to store rainwater. The idea of this design pattern is to find a mode of urbanization that has the least effect on the physical environment by refusing to continue to waterproof and modify rivers.

So in our case study and to ensure the sustainability of the storage facilities, the choice of alternative techniques were brought to opencast developments, visible and integrated urban development. The works of storage as shod with recommended structure are now multifunctional, both for reasons of reliability - made visible works are better maintained - and cost - this adds value to the significant capital investment and operation by integrating the book in a local project.

There are, in this design, a willingness to reverse the traditional logic, to move from a mainly technical expertise, developed and implemented in a sectored service running technocratic way to not only technical expertise but also organizational, involving a cross-functional urban services, as part of a shared territorial project. Proximity is first used here as class analysis of these transformations and as a principle for evaluating these new stormwater management practices and finally as a generalization factor of storm water management by combining two conventional techniques and alternatives.

\section{Conclusions}

The combination of conventional and alternative techniques to shown its effectiveness in terms of stormwater management, the case study shows that this design allows you to:

- Temporarily storing storm water upstream by a buffer effect, slow down and regulate the flows downstream.

- Infiltrer Unpolluted soil water, as much as possible.

Distinguish and separately treat polluted water and storm water runoff

- Manage as close to its point of fall, with passive solutions (not dependent on pumps, valves, sluice gates and pipes may become blocked, etc.), from the roof, for example with the green roofs, or near home, with valleys systems and restoration of functional wetlands
- Avoid Or limit runoff, which is a powerful water pollution factor and rapid transfers of pollutants downstream Fight against floods and droughts

- Réapprovisionner Groundwater

- Cost Reduced compared to conventional solutions (pipes, pumps)

Water is not an eternal resource. In many countries, it is a resource more than rare, it is sometimes wasted in outrageous fashion.

Also, everyone should contribute somewhat to its scale, to improve the situation. The combination of conventional and alternative techniques for the management of rainwater is one of the ways to save drinking water. They allow reuse of urban runoff water for irrigation and other daily uses. However, it is good to remember that the technique of grassed swales or ditches has a high cost and the return on investment is not really the intention. So this management should be as voluntary communal approach to save water more than an economical way to spend less.

\section{REFERENCES}

[1] Chaib. J. (1997). Rainwater - Integrated Management: A Practical Guide - Urban Ecology, Sand Edition of the Earth, $175 \mathrm{p}$.

[2] Larue. D. Da Silva. (2008). the landscape complementarity and hydraulic engineering, Atelier LD, GRAIE - 7th Conference Sustainable management and rainwater.

[3] Sustainable Building, Le Moniteur, Special Issue, March 2008.

[4] Enhance stormwater in town, Le Moniteur, 6 February 2009.

[5] The rainwater recovery system subject to conditions, Le Moniteur, July 6, 2007.

[6] Guide for the inclusion of stormwater and urban planning documents (collective work GRAIE, 2009).

[7] The control, treatment and recovery of rainwater, supports a bioclimatic city: 4 case studies, NOVATECH 2010 Piel. C., worse. M., Maytraud. T.

[8] New York City Department of Environmental Protection (NYCDEP). 2014. NYC Green Infrastructure Plan. http://www.nyc.gov/html/dep/html/stormwater/nyc green in frastructure_plan.shtml 